The Immunology
of Infant Feeding 
ETTORE MAJORANA INTERNATIONAL SCIENCE SERIES

Series Editor:

Antonino Zichichi

European Physical Society

Geneva, Switzerland

\section{(LIFE SCIENCES)}

Volume 1 BLADDER TUMORS AND OTHER TOPICS IN UROLOGICAL ONCOLOGY

Edited by M. Pavone-Macaluso, P. H. Smith, and F. Edsmyr

Volume 2 ADVANCES IN RADIATION PROTECTION AND DOSIMETRY IN MEDICINE

Edited by Ralph $\mathrm{H}$. Thomas and Victor Perez-Mendez

Volume 3 PULMONARY CIRCULATION IN HEALTH AND DISEASE Edited by $\mathrm{G}$. Cumming and $\mathrm{G}$. Bonsignore

Volume 4 SELECTED TOPICS IN EXERCISE CARDIOLOGY AND REHABILITATION

Edited by A. Raineri, J. J. Kellermann, and V. Rulli

Volume 5 THE AGING BRAIN: Neurological and Mental Disturbances Edited by G. Barbagallo-Sangiorgi and A.N. Exton-Smith

Volume 6 THE LUNG IN ITS ENVIRONMENT

Edited by $\mathrm{G}$. Cumming and $\mathrm{G}$. Bonsignore

Volume 7 INVESTIGATION OF BRAIN FUNCTION

Edited by $A$. W. Wilkinson

Volume 8 THE IMMUNOLOGY OF INFANT FEEDING

Edited by $\mathrm{A}$. W. Wilkinson 


\title{
The Immunology of Infant Feeding
}

Edited by

\author{
A. W. Wilkinson \\ Institute of Child Health \\ University of London \\ London, England
}




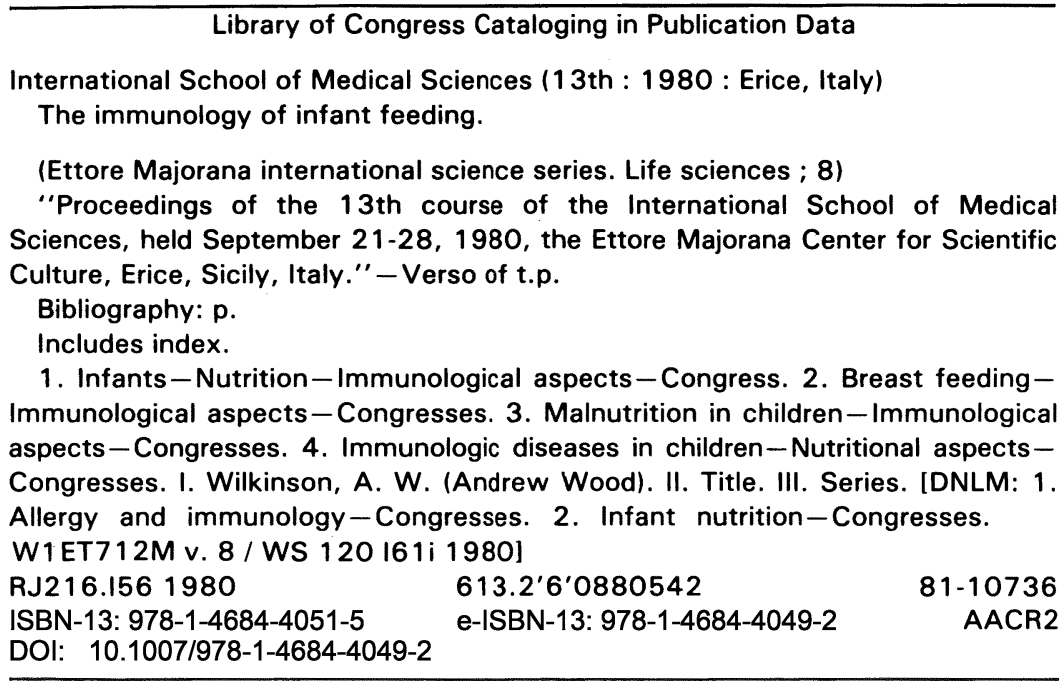

Proceedings of the 13th Course of the International School of Medical Sciences, held September 21-28, 1980, at the Ettore Majorana Center for Scientific Culture, Erice, Sicily, Italy

(c) 1981 Plenum Press, New York

Softcover reprint of the hardcover 1st edition 1981

A Division of Plenum Publishing Corporation

233 Spring Street, New York, N.Y. 10013

All rights reserved

No part of this book may be reproduced, stored in a retrieval system, or transmitted, in any form or by any means, electronic, mechanical, photocopying, microfilming, recording, or otherwise, without written permission from the publisher 
FOREWORD

Though much thought is given to nutritional aspects of infant feeding, the complex immunological aspects have not been considered adequately, not only in the acceptance of the change to artificial feeding during this century, but also in developing feeds for total or supplementary feeding which will do minimal immunological damage.

Besides food, mother's milk gives an orchestra of complex interacting bacteriostatic, bactericidal and anti-viral substances which contribute to the establishment of the normal intestinal flora. These mechanisms probably explain the many reports that breast fed babies get fewer infections than those fed artificially; deprivation from this effect of artificial feeding can be devastating in developing countries, with limited hygienic facilities, bad water supplies and sanitation. Infection is also more frequent in artificially fed infants in developed countries.

Ingesting antigens is an important step in initiating the immune response, but the response to such antigens is a controlled one, and besides antibody and cell mediated responses, partial tolerance, and immune exclusion (reduction of subsequent entry of antigen) occur. It is likely that food allergy, grossly neglected until recently, arises from disturbance of such mechanisms in the genetically vulnerable (immunodeficient) child.

The role of such common minor genetic heterogeneity on the risk of infection resulting from artificial feeding has been little studied. The development of atopic allergies is strongly influenced by adverse environmental factors in the neonatal period, one of which is infant feeding. In this book we consider mechanisms and genetic variation in response to, and the handling of ingested antigen, the mechanisms of protection transferred by the mother, the nature of the intestinal flora and the way in which artificial feeding and supplements affect it. The possibility that such changes in intestinal flora affect chronic immunopathology is also considered. 
It is also important, for immunological as well as other reasons, for the infant to have enough to eat. The adverse effects of malnutrition on antibody and cell mediated immune responses are a1so outlined, with recognition of the importance of the deterioration of infectious illness which accompanies weaning in developing countries, in the development of the syndromes of malnutrition. Finally, the implications of these factors for planning immunisation, milk banks, and artificial feeds are considered, and in particular whether feeds to supplement breast feeding should differ from those for total infant feeding. Finally suggestions are made for further fields requiring more study, and longer term and immediate research possibilities.

The principal deduction from the fruitful discussion at this lively meeting was the profound limitation of our knowledge of all aspects of this complex field. Nonetheless, there is plenty of evidence for the complexity of these inter-relationships, and the abandoning or supplementation of breast feeding is associated with some increased risk in all countries. The pressing need to prevent the spread of unnecessarily artificial feeding in developing communities, should not deflect us from awareness of our ignorance of the effect such changes may have had in developed countries. Immunological theory can suggest that many adverse effects, early and late, may arise from deprivation or inactivation of maternal protective systems, perhaps especially in some vulnerable individuals. The on 1y rational deduction is that such a physiological system should be left undisturbed, unless unavoidable, until we know for certain that it is safe to do so. 
CONTENTS

The Secretory Immune System . . . . . . . . . . . . 1 John Bienenstock

The Handling of Ingested Antigens . . . . . . . . 13

E.T. Swarbrick

Handling of Food Antigens and Their Complexes

by Normal and Allergic Individuals . . . . . . .

R.J. Levinsky, R. Pagane11i, D.M. Robertson, and D.J. Atherton

Bacteriostatic Systems in Human Milk . . . . . . . .

J.J.Bullen

Infant Feeding and the Faecal Flora . . . . . . . . 41

C.L. Bullen

Breast Feeding and Virus Infections . . . . . . . .

David Tyrrell

Factors Predisposing to Food Allergy . . . . . . . .

J.F. Soothill

Regulation of IgE Antibody Responsiveness by

Ingestion of Antigen and by Maternal

Influence . . . . . . . . . . . . . . . .

E1len E.E. Jarrett

Effects of Malnutrition on Specific Cel1-Mediated

Immune Responses . . . . . . . . . . . . .

R.K. Chandra

Antibody Affinity: Its Relationship to Immune

Complex Disease and the Effect of

Malnutrition . . . . . . . . . . . . . .

M.W. Steward, Madeleine E. Devey, and

M.C. Reinhardt 
Immunologica1 Implications of Alternatives to

Mother's Milk: I. Infant Formulas . . . . . . 107 Brian Wharton

Immunological Implications of Alternatives to Mother's Milk: II. Donor Milk . . . . . . . . Brian Wharton

Implications for Immunisation: The Milk IgA Antibody Response to Live and Inactivated Polio Virus Vaccines . . . . . . . . . . . . L.A. Hanson, B. Carlsson, F. Jalil, B.S. Lindblad, and A.-M. Svennerholm

Ind ex. . . . . . . . . . . . . . . . . . . . . 